\title{
OPTIMAL MAINTENANCE OF BELOW-GRADE CULVERTS
}

\author{
Massimiliano Luzi $^{1}$, Igal M. Shohet ${ }^{2}$
}

\begin{abstract}
In Israel, below-grade culverts are critical structure as they are essential points of the water transport network across the country. A lack of maintenance may create safety hazards and economic loss. The current maintenance strategy is that of breakdown maintenance. Such strategy has the drawback of high repair and maintenance costs. This study presents a methodology to determine the optimal maintenance strategy for below-grade culverts during their design life, by evaluating life cycle performances and life cycle costs. A field survey aimed at collecting critical data to develop a suitable deterioration pattern model. An exponential model was found to be the most significant statistically. A Markov chain model was implemented to determine the culvert life cycle performances and life cycle costs. A Maintenance Effectiveness Indicator (MEI) determines the best life cycle maintenance strategy among: breakdown, performance-based, and preventive maintenance. The best maintenance strategy was found to be the preventive. It provides with the highest cost effectiveness and allows for knowing the required budget in advance. Preventive maintenance strategy, which is strongly associated with Lean Construction, permits to save $80 \%$ of the resources required under the breakdown maintenance regime. The methodology can be extended to other assets of the roadway infrastructure.
\end{abstract}

Keywords: Asset management, culverts, markov chains, preventive maintenance.

\section{INTRODUCTION}

Maintenance of roadway infrastructure requires particular attention, especially those structures for which a lack of maintenance may pose safety hazards and economic damage (road closures, etc.). Balancing the required funds and the available budget has become essential in order to decide on the proper maintenance strategy for each asset.

In Israel, below-grade culverts are some of the critical structures that call for special consideration, as they are essential elements in the nation-wide water transportation network. Unfortunately, they do not receive the attention they deserve compared with other roadway elements, and they are being left to deteriorate until they reach the end of their service life.

\subsection{Research objective}

Given the actual condition of below-grade culverts in Israel, the need for an effective maintenance and management system for these assets is clear. This paper discusses a method to determine the optimal maintenance strategy for below-grade concrete culverts. The method aims to reduce the occurrence of failure events to a minimum, while keeping culvert performance and cost-effectiveness high.

$1 \quad$ M.Sc. Graduate Student, Ben-Gurion University of the Negev, Be'er Sheva, Israel; formerly Università Politecnica delle Marche, Ancona, Italy massimilianoluzi16@gmail.com

2 Associate professor, Department of Structural Engineering, Ben-Gurion University of the Negev, Be'er Sheva, Israel,igals@bgu.ac.il 


\section{LITERATURE REVIEW}

Bridges and pavements traditionally receive more attention than other transportation assets (Akofio-Sowah et al. 2013). Nevertheless, ancillary assets such as culverts need management systems as well, since their importance has very often been overlooked or underestimated (Bhattachar et al. 2007; Meegoda and Zou 2015). Salem et al. (2012) stated the importance of developing effective deterioration models for culvert management as they enable planners to predict culvert performance throughout its service life. The authors thus developed a deterioration model based on binary logistic regression to support management planning according to culvert repair priority.

A Culvert Information Management System (CIMS) was proposed by Bhattachar et al. (2007) to address the allocation of maintenance funds according to the culverts' need for inspection, rehabilitation, or replacement. According to the authors, the CIMS could also be used at project level to plan intervention strategies. Meegoda and Zou (2015) developed a similar model for culvert inventory and inspection management, so that the departments of transportation (DOT) can implement this model to categorize culverts and develop effective short- and long-term zoned maintenance planning.

The CIMS discussed by Bhattachar et al. (2007) was developed in greater detail two years later by Meegoda et al. (2009), where the authors illustrated that the CIMS can not only allocate budgets (Bhattachar et al. 2007), but also analyse and decide whether the culvert requires inspection, rehabilitation, or replacement. Moreover, the CIMS maintains an updated inventory database, performs condition-based maintenance under a given 3year budget, and summarizes results noting any anomalous trends.

Since the inspection of underground culverts may be critical (Perrin Jr. and Dwivedi, 2006), the need to consider below-grade culverts in asset management arises as well. The benefits of including such structures are the same as for regular culverts, and include the possibility to prioritize repair and maintenance, reduce rehabilitation and replacement costs, and decrease the number of failures.

Among the studies on culvert management models, the work of Cahoon et al. (2002) stands out. The authors developed a culvert management model to test the condition of culverts based on several parameters. According to the results of this study, 9 out of 33 parameters were found to be statistically significant for the evaluation of the need to repair or replace culverts. These nine parameters are: age of culvert, scour at outlet, evidence of major failure, degree of corrosion, wear of culvert invert, sedimentation of cross section, physical blockage, joint separation, and physical damage. In the present study, only two parameters are needed to evaluate culvert condition: age of culvert and culvert performance.

\section{RESEARCH METHOD}

\subsection{Field Survey}

The data on which the deterioration model in the proposed methodology is based was collected by means of a field survey of culverts throughout Israel. The survey was conducted mainly inland and in the centre of the country, so as to avoid the effects of high corrosive environments on the culverts. Moreover, culverts of different age and condition were examined in order to have sufficiently large and varied sample (David 2008). 
The survey procedure followed the national guidelines for the assessment of bridges and road structures in Israel (Netivei Israel National Transport Infrastructure Company Ltd, 2011), and covered 36 below-grade culverts.

The results are presented in two main categories:

- basic information (location, length, section, age, and significant images);

- culvert performance.

The culvert performance, $\mathrm{CP}$, is determined according to the severity and extent method (Sterritt 2002; Sterritt and Harris 2002) that is performed, at first, on visual observations. $\mathrm{CP}$ is a numerical score ranging from 1 to 5 , where 1 represents the best condition and 5 the worst.

Along with culvert performance, the culvert age constitutes the other indispensable parameter for the development of the methodology explained later on.

\subsection{Data Analysis}

Based on the survey results, the two key parameters, age and culvert performance, were correlated to identify a suitable deterioration model. Three models were examined: linear, logarithmic, and exponential, the latter of which best fitted the degradation trend (Figure 1). The reliability of such regression model was tested using the coefficient of determination, $r^{2}$, which displayed a high level of correlation (0.9416).

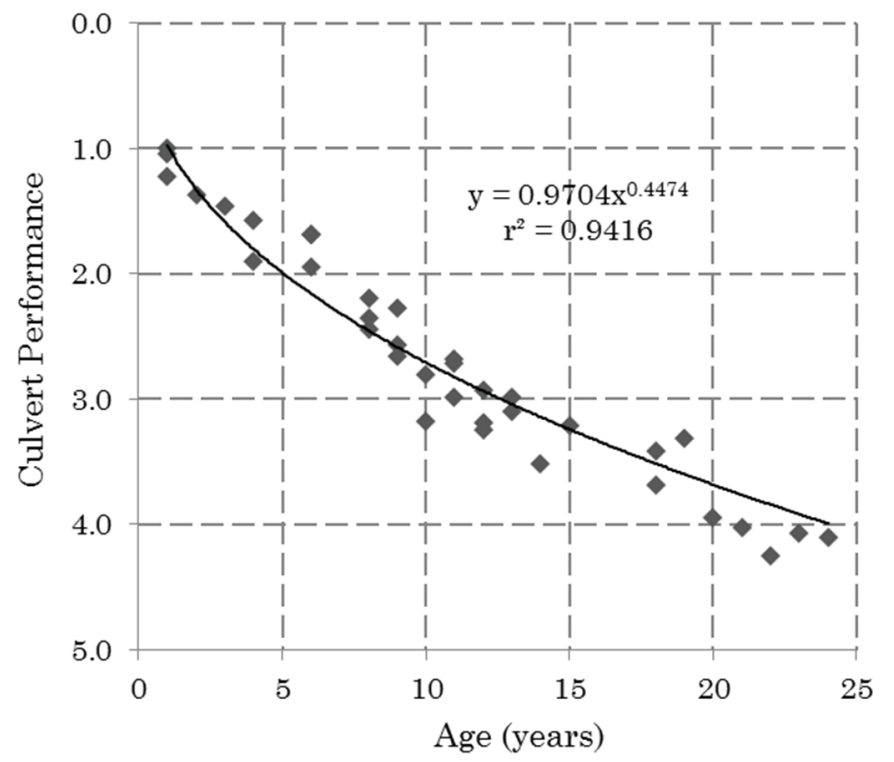

Figure 1: Below-grade culverts survey data points and exponential deterioration pattern

The next phase of the methodology was aimed at determining the future performance of culverts. To this end, the distribution of the field survey results was subjected to statistical analysis. A chi-squared $\left(\chi^{2}\right)$ test revealed that the results have a $92 \%$ probability of being normally distributed. The probability of deterioration from a given initial state was calculated according to that distribution, based on the exponential model. Moreover, the statistical occurrence of the deterioration was tested, and they were found to be statistically independent. 


\subsubsection{Transition Probability Matrix (P)}

The culverts future condition is predicted by a transition probability matrix that specifies the probability of the culvert being in a certain state of deterioration after one year. Based on the 5-point performance scale defined above, four performance levels were identified: $1-2,2-3,3-4$, and $4-5$. Table 1 provides the transition probability matrix of culverts' deterioration process. The convenience of using performance levels to assess the condition of structures is well known; it enables to forecast the asset's life expectancy and future deterioration condition by conducting visual observations in the present (Thompson, 2012).

Table 1: Transition Probability Matrix $(P)$.

\begin{tabular}{ccccc}
\hline & $1-2$ & $2-3$ & $3-4$ & $4-5$ \\
\hline $1-2$ & 0.88 & 0.12 & 0 & 0 \\
$2-3$ & 0 & 0.95 & 0.05 & 0 \\
$3-4$ & 0 & 0 & 0.96 & 0.04 \\
$4-5$ & 0 & 0 & 0 & 1 \\
\hline
\end{tabular}

\section{RESUltS AND DiscUSSION}

This chapter describes the implementation of the Markov chain-based model for the determination of life cycle performance and life cycle cost associated with culvert maintenance.

\subsection{Life cycle performance}

To determine the optimal maintenance strategy, three different maintenance policies have been tested:

- Breakdown maintenance (BM): according to this policy, the restoration of damaged structures takes place only after the functionality has been compromised. Despite the fact that no funds are needed for maintenance planning, upon the occurrence of failure, the need for an immediate solution often results in higher costs due to unplanned repair work.

- Performance based maintenance (PBM): this policy seeks to keep structure performance above previously agreed levels, and maintenance operations are carried out only when the current performance no longer meets the required needs. This strategy allows for a good use of resources and funds, reducing the uncertainty regarding maintenance costs.

- Preventive maintenance (PM): the purpose of preventive maintenance is to extend the service life of assets by performing minor repairs and local interventions, in order to delay the need for total reconstruction and/or renewal. To achieve this, the maintenance program is scheduled over a certain time frame so that the structure and its components can be managed optimally. The application of preventive maintenance programs results in an effective extension of the asset's service life (Lwin, 2006). Preventive Maintenance is highly associated with Lean Concept (El Sakka et al., 2016). 
Combining the aforementioned transition probability matrix, $P$, with one of the three maintenance policies, the life cycle performance matrix, $\Pi$, is obtained. This matrix describes the performance condition under a given maintenance policy through the entire life cycle of the culvert, which is usually expected to be 30-50 years (Wuorenjuuri, 2014). In this study, the culvert designed life cycle is assumed to be 50 years, as defined by the standard for service life design ISO15686-1:2006 (International Organization for Standardization, 2011).

$$
\Pi=\lim _{n \rightarrow 50}(M P \cdot P)^{n}
$$

The life cycle performance matrix $\Pi$, generally referred as the stationary distribution of the process (Ross, 2014), provides the likely performance condition at which the culvert is expected to be found after 50 years of maintenance, according to one of three maintenance policies defined above. It should be noted that the expected state of the culvert at the end of its life cycle is different for each maintenance policy. Table 2 and Table 3 report the BM policy matrix and the PM policy matrix, respectively, employed in this study.

Table 2: Breakdown maintenance policy matrix (BM)

\begin{tabular}{ccccc}
\hline & $1-2$ & $2-3$ & $3-4$ & $4-5$ \\
\hline $1-2$ & 1 & 0 & 0 & 0 \\
$2-3$ & 0 & 1 & 0 & 0 \\
$3-4$ & 0 & 0 & 1 & 0 \\
$4-5$ & 1 & 0 & 0 & 0 \\
\hline
\end{tabular}

Table 3: Preventive maintenance policy matrix (PM)

\begin{tabular}{ccccc}
\hline & $\mathbf{1 - 2}$ & $\mathbf{2 - 3}$ & $\mathbf{3 - 4}$ & $\mathbf{4 - 5}$ \\
\hline $1-2$ & 1 & 0 & 0 & 0 \\
$2-3$ & 1 & 0 & 0 & 0 \\
$3-4$ & 1 & 0 & 0 & 0 \\
$4-5$ & 1 & 0 & 0 & 0 \\
\hline
\end{tabular}

The culvert life-cycle performance results from the inner product of the occurrence probabilities of each performance level and the performance level vector, $\lambda$ :

$$
L C P=\langle\operatorname{mean}(\Pi), \lambda\rangle
$$

where mean $(\Pi)$ is a row vector obtained by averaging the matrix $\Pi$ along its columns, and $\lambda$ is a column vector that assumes the performance value associated with each of the four performance levels: $\lambda=\left[\begin{array}{llll}1.5 & 2.5 & 3.5 & 4.5\end{array}\right]^{\mathrm{T}}$.

The average performance of the culvert for the life cycle, $L C P$, is $2.88,2.25$, and 1.62 for the breakdown maintenance policy, the performance-based maintenance policy, and the preventive maintenance policy, respectively. 


\subsection{Life cycle cost}

The maintenance of each culvert component involves different operations and the deployment of different kinds of resources. Therefore, the overall culvert maintenance cost have been arranged in three component categories as follows:

- Concrete components cost matrix (CC)

- Joints and sealing components cost matrix (JSC)

- Flow and slope stability components cost matrix (FSC).

These maintenance costs, expressed in thousands of New Israeli Shekels ${ }^{3}$ (NIS), were calculated for a 5-year maintenance planning horizon, and they include the cost of materials, workmanship, and special equipment if needed. Indirect costs due to the closure of roads and traffic arrangements were also taken into account.

The life cycle maintenance cost for a designed service life of 50 years, $L C C$, for one of three component categories and a given maintenance policy, is calculated by combining the life-cycle performance matrix $\Pi$ with the appropriate cost matrix, averaging the resulting matrix along the columns, summing up its components, and multiplying the sum by 10 :

$$
L C C=\sum \operatorname{mean}(\Pi \cdot C) \cdot 10
$$

where $C$ is one the cost matrix defined above.

The average life-cycle maintenance cost for the preventive maintenance strategy is far lower than for the breakdown maintenance strategy. For example, for concrete components, the costs for the preventive and breakdown maintenance policies are 234,000 NIS and 1,674,000 NIS, respectively.

\subsection{Maintenance Effectiveness Indicator}

The last stage of the methodology consists of the determination of a maintenance effectiveness indicator (MEI) that addresses the selection of the optimal maintenance strategy throughout the culvert's life cycle.

The MEI expresses the relationship between the overall culvert performance, $L C P$ and the average maintenance cost, $L C C$, over the designed life cycle that is assumed to be 50 years:

$$
M E I=\frac{1}{L C P \cdot L C C}
$$

the higher the indicator, the greater the benefit.

The MEI was calculated for each of the three component categories and was combined with all three maintenance policies; therefore, nine scenarios were evaluated, the results of which are summarized in Figure 2.

Figure 2 shows that the preventive maintenance policy is the most cost effective for all of the component categories. This means that PM represents the best alternative in terms of both performance and costs.

\footnotetext{
${ }^{3} 1$ NIS $\approx 0.28$ US\$ (July 2017)
} 


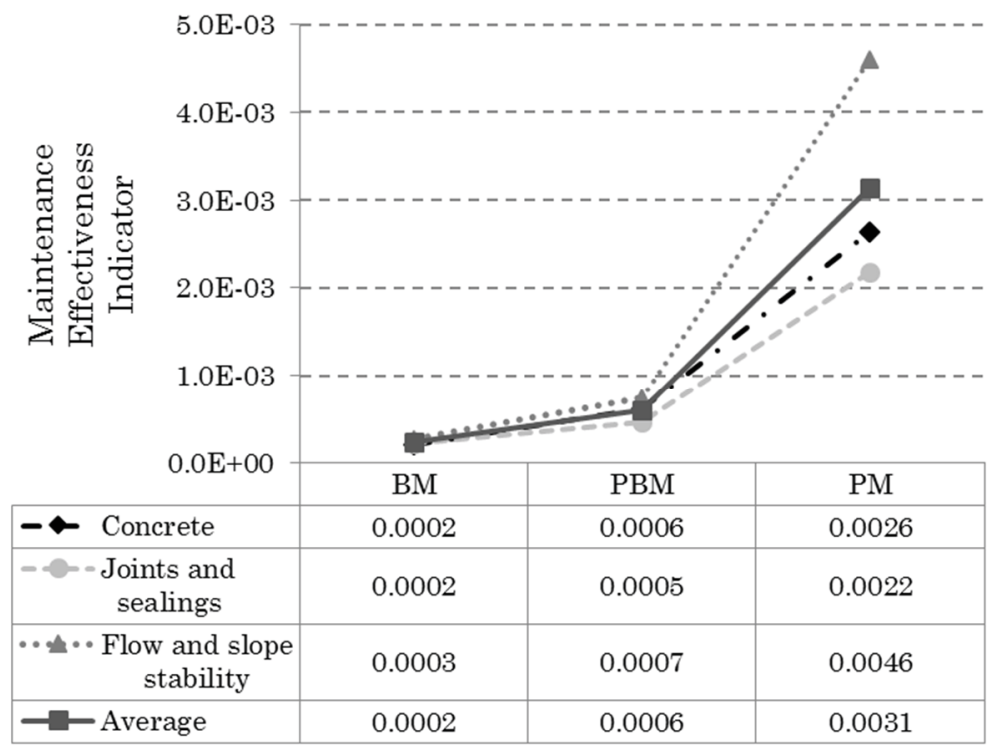

Figure 2: Maintenance Effectiveness Indicator for different maintenance policies

\section{CONCLUSIONS AND RECOMMENDATIONS}

This paper aimed to examine the optimal strategy for the maintenance and management of below-grade concrete culverts. A field survey showed that below-grade culverts do not receive enough attention and deteriorate until they reach the end of their service life. The development of a method for the selection of the optimal maintenance strategy for these assets was, therefore, warranted, and a probabilistic Markov chain-based methodology was introduced to achieve this. In order to determine average performance and cost of maintenance for the designed life cycle of the culvert, three categories of components were identified, and three maintenance policies were investigated for each category. To prove the effectiveness of the methodology, a maintenance effectiveness indicator was developed. Such indicator reflects the long-term performance and cost of a generic maintenance policy by means of a numeric value. With regard to the three maintenance policy considered in this paper, the preventive maintenance policy provides the highest costeffectiveness, allowing for $80 \%$ saving of the resources required for maintenance under the breakdown maintenance regime. On a life-cycle scale, it was demonstrated that this policy reduces the probability of failures and leads to the highest performance.

Further possible developments include extending this methodology to other areas, such as residential building and public facilities. Moreover, the decision tool can serve the purpose of performance-based maintenance for the same assets. The synergistic objective of this research is to create awareness for the monitoring, management and maintenance of any kind of deterioration-prone asset.

\section{REFERENCES}

Akofio-Sowah, M.A., Boadi, R., Amekudzi, A., Meyer, M. (2013). Managing ancillary transportation assets: The state of the practice. Journal of Infrastructure Systems, 20, doi: http://dx.doi.org/10.1061/(asce)is.1943-555x.0000162.

Bhattachar, D., Najafi, M., Salem, O., Funkhouser, P., Salman, B. (2007). Development of an asset management framework for culvert inventory and inspection. Pipelines 2007: 
Advances and Experiences with Trenchless Pipeline Projects - Proceedings of the ASCE International Conference on Pipeline Engineering and Construction, pp. 1-11, doi: http://dx.doi.org/10.1061/40934(252)76.

Cahoon, J., Baker, D., Carson, J. (2002). Factors for rating condition of culverts for repair or replacement needs. Transportation Research Record, pp. 197-202, doi: http://dx.doi.org/10.3141/1814-23.

David, E., 2008. Probabilistic model for maintenance of below-grade culverts. M. Sc. thesis, Ben-Gurion University of the Negev. (In Hebrew).

El Sakka, F., Eid, K., Narciss, T., Hamzeh, F. (2016). Integrating Lean into Modular Construction: A Detailed Case Study of Company X. Proceedings of the 24th Annual Conference of the International Group for Lean Construction; IGLC 24, Boston; United States, section 8, pp. 23-32. URL http://www.iglc.net/.

Lwin, M. (2006). The important roles of bridge maintenance and management on transportation safety and efficiency. Proceedings of the 3rd International Conference on Bridge Maintenance, Safety and Management - Bridge Maintenance, Safety, Management, Life-Cycle Performance and Cost, pp. 47-51, URL: https://www.crcpress.com/.

International Organization for Standardization. (2011). ISO 15686-1:2006 Buildings and constructed assets - Service life planning - Part 1: General principles and framework. Technical Report. International Organization for Standardization. URL: www.iso.org.

Meegoda, J., Juliano, T., Tang, C. (2009). Culvert information management system. Transportation Research Record, pp. 3-12, doi: http://dx.doi.org/10.3141/2108-01.

Meegoda, J., Zou, Z. (2015). Long-term maintenance of culvert networks. Journal of Pipeline Systems Engineering and Practice, 6, doi: http://dx.doi.org/10.1061/(ASCE)PS.1949-1204.0000194.

Netivei Israel National Transport Infrastructure Company Ltd. (2011). Guidelines for assessment of bridges and road structures. Technical Report. URL: https://www.iroads.co.il/en.

Perrin Jr., J., Dwivedi, R. (2006). Need for culvert asset management. Transportation Research Record, 8-15, doi: http://dx.doi.org/10.3141/1957-02.

Ross, S.M. (2014). Introduction to probability models. Academic press. ISBN: 9780124079489.

Salem, O., Salman, B., Najafi, M. (2012). Culvert asset management practices and deterioration modelling. Transportation Research Record, 1-7, doi: http://dx.doi.org/10.3141/2285-01

Sterritt, G. (2002). Bridge Condition Indicators, Volume 1, Commission report. Technical Report. WS Atkins Consultants Ltd., CSS Bridges Group. URL: http://tap.iht.org.

Sterritt, G., Harris, S. (2002). Bridge Condition Indicators, Volume 2, Guidance Note on Bridge Inspection Reporting. Technical Report. WS Atkins Consultants Ltd., CSS Bridges Group. URL: http://tap.iht.org.

Thompson, P. (2012). Estimating asset deterioration and life expectancy by using levels of service. Transportation Research Record, pp. 19-26, doi: http://dx.doi.org/10.3141/2285-03

Wuorenjuuri, J. (2014). Management of railway culverts in Finland Bridge. Maintenance, Safety, Management and Life Extension - Proceedings of the 7th International Conference of Bridge Maintenance, Safety and Management, IABMAS 2014, pp. 17391742, doi: http://dx.doi.org/10.1201/b17063-266. 